Peppler, K., Warschauer, M., \& Diazgranados, A. (2010). Game Critics: Exploring the Role of Critique in Game-Design. E-Learning, 7(1), pp. 35-48.

\title{
Game Critics: Exploring the Role of Critique in Game- Design Literacies
}

\author{
Kylie Peppler \\ Indiana University, Bloomington \\ Mark Warschauer \\ University of California, Irvine \\ Alicia Diazgranados \\ Los Angeles Unified School District
}

\begin{abstract}
Digital games have become a major part of the $21^{\text {st }}$ century learning environment, but little attention has been paid to understanding what young learners already know about games and how this understanding can be used as a bridge to academic literacy. In this study, we analyze second-grade students' efforts at critiquing digital games. Students collectively developed and applied their own standards for evaluating three computer-based games, coming up with criteria similar to those used by professional game designers. Students defended their evaluations using logic and reasoning, thus practicing important thinking and argumentation skills that are often overlooked at the elementary school level. In class discussions of their evaluations, they were exposed to the kinds of specialized language required for the development of academic language proficiency, and, in writing about their critiques, they produced longer and more sophisticated texts than those they wrote for other assignments.
\end{abstract}




\section{Introduction}

Video games have become an important entry point for many young people into "digital literacy, social communities, and tech-savvy identities" (Salen, 2007, p. 302). Many consider video gaming as a cultural medium in its own right and the skills associated with playing, modding, and designing games as new literacies (Buckingham \& Burn, 2007; Salen, 2007). Being literate in this domain entails system-based thinking, iterative critical problem solving, understanding art and aesthetics, writing and storytelling, interactive designing, applying game logic and rules, and programming. While a great deal of attention has been paid to the merits of video game play, a focus on game design literacy also calls attention to the value of producing one's own video games and the habits of mind that support the creative production process.

As young people play video games, they learn the subtle and inexplicit rules that guide good game design. Understanding such rules of the medium is a critical step in creating one's own games, as well as in generating informed opinions about preexisting ones. Our prior work has demonstrated that youth can become critical game designers over the course of engaging in creative production during the after-school hours, as evidenced by the intentionality of messages found in youths' media artwork (Peppler \& Kafai, 2007a). However, these same youth have difficulty talking about their work as articulately as they express their ideas in visual/multimedia format. This is why formalized critique can be an important part of the learning process. In order to become good designers, youth must become skilled at constructively critiquing what they have learned in order to creatively extend and apply their understanding. Here we can build upon work in the arts, which has demonstrated that opportunity for critique is imperative to help youth develop into critical and creative producers (Hetland et al., 2007; Levi \& Smith, 1991, Dewey, 1934/1980). Through a process of critique, youth can defend their analyses using language specific to the task while internalizing content matter and knowingly applying it toward the evaluation of authentic practices.

Moreover, learning to critique and create video games potentially connects to academic literacy. Much of the prior work in New Literacy Studies has uncovered multiple literacies in unexpected places (see, e.g., Moje, 2000; Wohlwend, 2009). More recently, academics and practitioners are looking for ways to use these new literacies that are rooted in youth culture to promote academic forms of discourse (e.g., Morrell \& Duncan-Andrade, 2004; Marsh, 2005; Millard, 2003). The current research is an exploration into how video games can be used as a bridge between new literacies rooted in youth culture and academic literacies (Intersegmental Committee of the Academic Senates, 2002). 
This study examined 40 second-grade students in two classrooms who participated in a four-day unit on critiquing games designed in the visual programming environment, Scratch (Maloney et al., 2004). Viewing the theory of literacy as a social practice, we utilized a qualitative design that analyzed data from transcribed small and large group discussions, student writings, and classroom artifacts, focusing on the following research questions:

1) What kind of culture of critique emerges among young children examining videogames?

2) In what ways, if any, does critiquing games appear to contribute to the development of young children's academic literacy?

While prior work has focused on game design in informal settings (Kafai, 1995; Peppler \& Kafai, 2007a; Peppler \& Kafai, 2007b), there are additional affordances of adopting game design in the classroom setting. There is an opportunity for youth to reflect on peer and professional work, make systematic evaluations, share opinions, and develop general logic and reasoning skills relevant in other subject areas, such as math, science, and language arts. This could be an important addition to the elementary school curriculum, which - especially in urban schools - typically includes too few opportunities to justify opinions around complex issues that may not have right and wrong answers. To our knowledge, a formalized curriculum around the critique of existing games, either in the classroom or in out-of-school educational settings, has not yet been widely implemented. By building on children's existing knowledge of video games, we can capitalize on their recreational interests in the out-of-school hours, providing a rich context for successful bridges to academic forms of literacy at the heart of the school curriculum.

\section{Literacy in the $21^{\text {st }}$ Century: Bridging the Divide}

We adopt for this study a New Literacies framework, which posits that literacies are best understood as a set of social practices that can be inferred from events and are mediated by written, visual, and other types of texts (Barton \& Hamilton, 2000; Bruce, 2002). Hence, the basic unit of a social theory of literacy is that of literacy practices, defined as the general cultural ways of utilizing language (Barton \& Hamilton, 2000). Fundamental to this understanding is the notion that practice reflects the body of ideas and beliefs or ideology of an individual or a group (Street, 1993). Although literacy practices are not observable units of behavior, since they also involve values, attitudes, feelings, and social relationships, one can observe literacy events being mediated by texts (Barton \& Hamilton, 2000; Street, 1993). Accordingly, texts are a crucial part of literacy events and the study 
of literacy is partly the study of texts and how they are produced and used (Barton \& Hamilton, 2000). Researchers from a variety of fields have demonstrated that a text is no longer only a sequence of alphabetic characters on paper; rather, social arrangements such as tagging, type of dress (Moje, 2000), singing, drawing, and dancing (Gallas, 1994), can all be viewed as texts. The texts that will be the focus of this study will be the video games included in the unit as well as the classroom writings and discussions that surrounded these texts.

Within a wide field of new literacies (e.g., oral literacy, visual literacy, information literacy, scientific literacy, emotional literacy, etc.), literacy educators and researchers have analyzed videogames and put forth theories of gaming literacies (Squire, 2005; Salen, 2007; Buckingham \& Burn, 2007). This work has broadened our notions of literacy to include new literacies that are part of game design and game play, including the literate practices of gamers in MMOs and other gaming environments (Steinkuehler, 2007).

And yet, in the attempt to find literacy in everyday activities, something is lost. The reality is that reading, writing, and critiquing traditional print genres are still important societal skills and act as gatekeepers for our youth, who face high school exit exams and an amalgam of standardized tests. These challenges only intensify in college, when professors expect entering students to have the ability to read, write and think critically (Intersegmental Committee of the Academic Senates, 2002). The field of academic literacy spans these content areas and has identified that wellprepared students, who have the habits of mind or the foundational dispositions for academic reading, writing, and critical thinking, are able to use technology for educational means and are able to listen and speak English beyond conversational fluency.

However, the educational gap that we see in college begins much earlier evidence points to the gap beginning as early as fourth grade, when students begin to read to learn instead of just learning to read (Chall, 1996). Starting in fourth grade, English Language Learners, especially those from low socio-economic backgrounds, are particularly at risk in the current schooling system. However, well-designed new technologies and computer-mediated instruction have been found to be a valuable tool to mediate learning and communication, particularly for English Language Learners (Cummins, 2008; Warschauer, Grant, Del Real, Rousseau, 2004). This is a promising finding that has yet to be fully capitalized on in schools.

At the same time, several scholars have begun looking at the New Literacy Studies as a bridge to academic literacy and as a springboard for fostering critical discourse (Morrell \& Duncan-Andrade, 2004; Millard, 2003; 
Marsh, 2005). For example, Morrell and Duncan-Andrade (2004) have explored the role of hip-hop as a bridge to reading canonical poetry, closely examining how youth can make connections between their out-ofschool and in-school literacy practices and between pop and high culture. Others in the field are calling this approach to classroom pedagogy a "literacy of fusion" (Millard, 2003). This study extends existing research on the New Literacy Studies, and particularly work on gaming literacies, to explore digital games as a context for fostering academic literacy in the classroom. Moreover, we have focused particularly on the role of specialized language and critical analysis in academic literacy development. As Gee (2004) argues, youth need specialized language, as opposed to everyday language, to succeed in schools. High socioeconomic status (SES) youth tend to get this at home, while this tends not to be the case for low SES youth. Much like Gee, we argue that communication in and around games can be one excellent way to build specialized language.

\section{Lessons from Arts Education}

In trying to bridge the divide between the classrooms and the out-of-school learning experiences of the children in our study, we drew on literature from the field of arts education and, particularly, on the role that critique can play in the learning and design process. We chose to focus on critique (Dewey, 1934; Hetland et al., 2007; Levi \& Smith, 1991; Soep, 2005) rather than on the traditional notion of critical analysis oftentimes found in the media education curriculum (see Buckingham's 2003 work on "becoming critical") because of the limited timeframe and emphasis on design that were central to the unit in this study. Hetland et al.'s (2007) Studio Thinking Framework focuses principally on the role of critique in fostering the habits of mind promoted in the visual arts. In their work, they discover that learning to critique fosters reflecting on, questioning, explaining, and evaluating what makes one work better or more effective than another. While often in the context of the visual arts, students are critiquing their own work; in the context of this study, children were critiquing the work of others. The Critiquing Games unit was intended to be a starting point for the conversation-for kids to think about the lines between creative production and game design - and provide a foundation for youth to draw upon as they started designing their own video games.

\section{Research Context, Tools, and Pedagogy}

This study took place at an at-risk elementary school in Los Angeles Unified School District that has low scores on standardized tests. The majority of the students were English Language Learners (ELLs) and a 
large percentage of students qualified for a free or reduced price lunch. We observed two separate classes of second graders during their departmentalized mathematics class - a total of 40 students. The majority of these students performed far below basic levels of math and language arts at the start of the study and $25 \%$ of the students were designated as having special needs. Students were evenly split between native Spanish and Korean speakers, with the exception of a small minority of native English speakers or students that were designated as English-Only.

\section{Local Practices}

This study was guided by theories of situated learning (Lave \& Wenger, 1991) and social theories of literacy (New London Group, 1996; Barton \& Rivet, 2004; Barton, 1991; Barton \& Hamilton, 2000; Gee, 1996; Moje, 2000). Central to these theories is the notion of communities of practice, which serve to support the values and behaviors to be learned (Lave \& Wenger, 1991). In the classrooms observed in this study, there were several important local practices - practices that surrounded the gaming culture specific to the classroom community. In this study, we sought to document and describe these local practices, which set the stage for the type of learning that took place in the classroom. Two sets of local practices, which developed throughout the school year, provided the foundation for the current study. The first set of local classroom practices evolved around students' progressive familiarity with technology. Students operated individual laptops in the classroom and used the media-rich programming environment, Scratch (Maloney et al., 2004; Resnick, Kafai, \& Maeda, 2003). An interactive whiteboard ${ }^{1}$ was used to dynamically shape group discussions. These local practices ensured that all students had a general level of technology fluency (National Research Council, 1999) at the start of the current study. The second set was a year-long gaming curriculum that familiarized the students with gaming concepts, rules of play, and a variety of educational and commercial games. This gaming curriculum was integrated into the students' math instruction due to its connections to issues of logic and reasoning, as well as the math instructor's special interest in gaming and technology.

\section{The Critiquing Games Unit}

One unit was chosen for the focus of this study, Critiquing Games, which occurred late in the school year and built upon both of these foundational

\footnotetext{
${ }^{1}$ Interactive whiteboards use a touch-sensitive display and connect to a computer and digital projector to display the computer image on the whiteboard screen. Computer applications can then be directly controlled from the display and whiteboard notes can be written in digital ink and saved to share later.
} 
practices. The unit took four days to complete over a period of two weeks. On Day One of the unit, students were asked to play three non-commercial games in Scratch - titled Fish Chomp, Treasure Quest, and Pinball -and discuss them in small groups as well as write down their observations. The games contained a range of gaming components, such as the ability to track points, to win or lose, levels, and various types of user interaction ${ }^{2}$. All three games had been originally produced by youth and then refined by the Scratch programmers at MIT to be included as sample games within Scratch. With limited guidance, students were instructed to discuss what they liked and disliked about the games as well as what they might do to improve the games. Afterwards, they were individually asked to write down their observations. On the second and third day, the classroom teacher recorded the group consensus about each game on the interactive whiteboard. On the last day, students used their observations to create a classroom rubric for evaluating games and then deployed that rubric to vote on each game. Classroom conversations were video recorded, transcribed, and later analyzed for this paper. The unit was repeated in the second participating classroom and was taught by the same instructor (who is the third author of this paper). The Critiquing Games unit was used as a starting point for students to imagine what kind of games they might mod or create in Scratch in the final weeks of the school year.

\section{Data Sources and Analysis}

The findings from the two classrooms are presented here as a compiled case, drawing from archival data as well as recorded observations to answer the two research questions stated above. In order to answer these questions, we drew upon four data sources collected during the aforementioned unit on critiquing games. First, we transcribed the baseline discussions of the games among the small groups of four students after playing the games. In each class there were five discussion groups of four children each. Three discussion groups were randomly chosen from each class to be included in the analyses (for a total of six small group discussions). Second, we collected the individual writings of the students evaluating each of the games. Both of these data sources were collected prior to the classroom teacher's mediation of the topic and prior to any classroom instruction on the topic. Third, we transcribed whole class conversations on creating a rubric for evaluation and took screenshots of the notes taken on the whiteboard by the teacher from large group discussions, the agreed-upon classroom scoring rubric, and the resulting graphs of how the children scored the game projects.

\footnotetext{
${ }^{2}$ A short description of the games as well as an accompanying screenshot can be found in Table 1.
} 
A top-down approach to coding was derived from the literature on gaming literacies, critique, and academic literacy (Chi, 1997). In particular, three top-down codes were used: the first was used to code and categorize the specialist language of videogames into several subcategories (e.g., core mechanics, game components, rules, goals, programming commands); the second was used to capture the emergent culture of critique (e.g., reflection, practice, value judgments); the third was used to capture academic literacy in the context of digital games, particularly the habits of mind involved (e.g., responding to divergent views respectfully, articulating ideas, thinking analytically about one's own ideas as well as others, contributing to academic discussions, challenging beliefs, seeking out other viewpoints, and evaluating evidence) as well as evidence of reading and writing critically (e.g., arguing, comparing, owning an idea, analyzing, reflecting, imagining other possibilities, using past experience, making observations, and supporting claims). Although the work on academic literacy is intended to prepare students to work with traditional canonical texts, the same habits of mind are applied here in the context of digital game critiques. The goal of these sets of codes was to capture the specialized language and habits of mind that emerged over the course of the discussions of the three digital games.

\title{
Culture of Critique
}

We turn to our first research question to investigate what kind of culture of critique emerges among young children examining videogames. In the unstructured small group discussions, conversations about whether the games were good, boring, hard, or easy emerged with warrants for these claims. In addition, the children in this study were able to support and encourage whole group participation and value differing opinions, which tie to academic literacy goals including the habits of mind and learning to listen and speak in small groups. The following excerpt was transcribed from the small group discussions and is representative of the conversations that ensued between the students while discussing the games:

\author{
Peer-Group \#4B discussing Fish Chomp \\ Student 1: I don't like it 'cause it's hard to catch the \\ fish. \\ Student 2: It's hard to select the fish? \\ Student 1: Yeah. That I don't like and I lost interest. \\ Student 2: Totally. \\ Student 3: You have to chase the fish. \\ Student 4: I like the fish and I like this game because \\ the big fish eats the small fish and it \\ makes sounds...
}


Student 1: But I don't like it is that I have to chase the fish and it's hard to catch them...

Student 2: Your turn.

Student 1: The fish come out of nowhere and you gotta try to catch them so the big fish can eat them, and that's it. I don't really like it.

Student 3: It has lots of colors...and I like it.

In this excerpt, it is interesting to note that while engaging in their critiques, the students focused on aspects of the game important to game designers, such as the level of difficulty, aesthetics, sound design, and goals of the game. This is an important starting point for acquiring the specialized language of game design. Additionally, students in this excerpt were able to formulate opinions (i.e., disliking the game) and justify their opinions rationally (i.e., hard to catch the fish). The students made and justified claims (i.e., formulating an opinion and justifying their rationale), which are important to developing academic literacy (especially developing the habits of mind as well as learning to read and write critically). Moreover, these practices are also relevant in the context of science, where lengthy discussions have taken place on the value of scientific argumentation. Similar to Steinkuehler's earlier findings on scientific habits of mind in MMOs (in press), the forms of scientific argumentation were prevalent within this context given that prior research indicates that such practices do not come instinctively and are difficult to cultivate (Kuhn, 1991; Osborne, Erduren, \& Simon, 2004). Taken together, these findings may suggest that games may be a particularly good context to foster rich discussion in schools.

This type of critique naturally leads to solution finding and the entertaining of hypothetical notions about how the games could be changed or modded in future iterations. In the following excerpt from the small group conversation, students were able to extend their critiquing practices by re-envisioning "improved" versions of the games based on their personal preferences:

Peer Group \#2A discussing Fish Chomp and Treasure Quest

Student 3: $\quad$...And also - the little fish were going faster than the big fish.

Student 4: ...I don't like it really... because the fish goes super slow, rrrrrrrrrr, and then when you finish here, the fish is here, he goes up and then I like to go up again...

...[Break]... 
Student 3: $\quad$ If I could change one thing [about Treasure Quest] if I just -

Student 4: Write it down somewhere!

Student 3: What if you just kicked the treasure?

Student 4: I would change on level two, the treasure. I would make it fall slower...

Student 3: $\quad$ That'd be even better.

The children in this study had no prior experiences modding existing video games but could readily see the possibilities in this exercise. This type of thinking is a good way to set the stage for future game design, as seemingly modest ideas like the ones stated above can introduce students to the depth of video game design concepts, ranging from changes of sprite costume and programming commands to the directions and logic of the game.

On the third day, both classes engaged in the formulation of scoring rubrics that would determine the assessment criteria for judging the quality of future games. They generally agreed upon five key elements of welldesigned games, including having instructions, levels, points, a win/lose element, and having a background (see Figure 2A and 2B). In doing so, they made comparisons between the games and relied upon their value judgments and reflections, connecting to another core part of what it means to read and write critically. There are some notable absences here when this rubric is compared against the individual writings. The rubric heavily privileged the game components, or the "what" in the videogames, while in the individual writings there was a great deal of attention paid to the core mechanics of the games, the logic/rules, as well as the playability or user-interface design issues (i.e., the how and why of the games). This may have been in part because individual game components were easy to discuss and agree upon while the other aspects of the video game that made something fun, hard, or boring were less easily discussed and agreed upon by the class. In other words, there may have been a misconception that simply having a timer, points, and a background would make a better game. Regardless, simply examining the rubric and not the content of the large group discussion would not have revealed the more nuanced articulations of the students. 


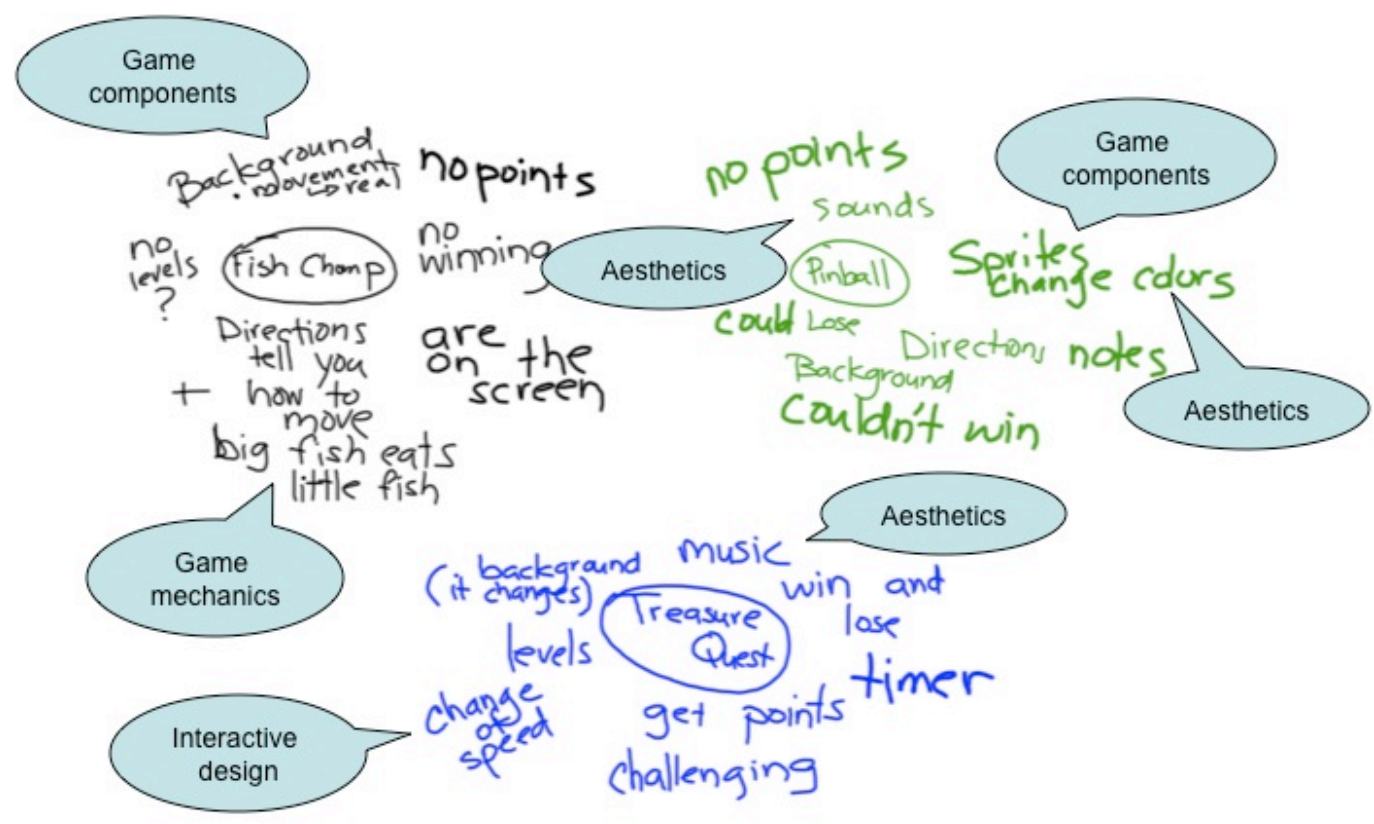

Figure 2A: Concept maps capturing the whole class discussions of elements of game design and thought bubbles calling attention to the coded categories.

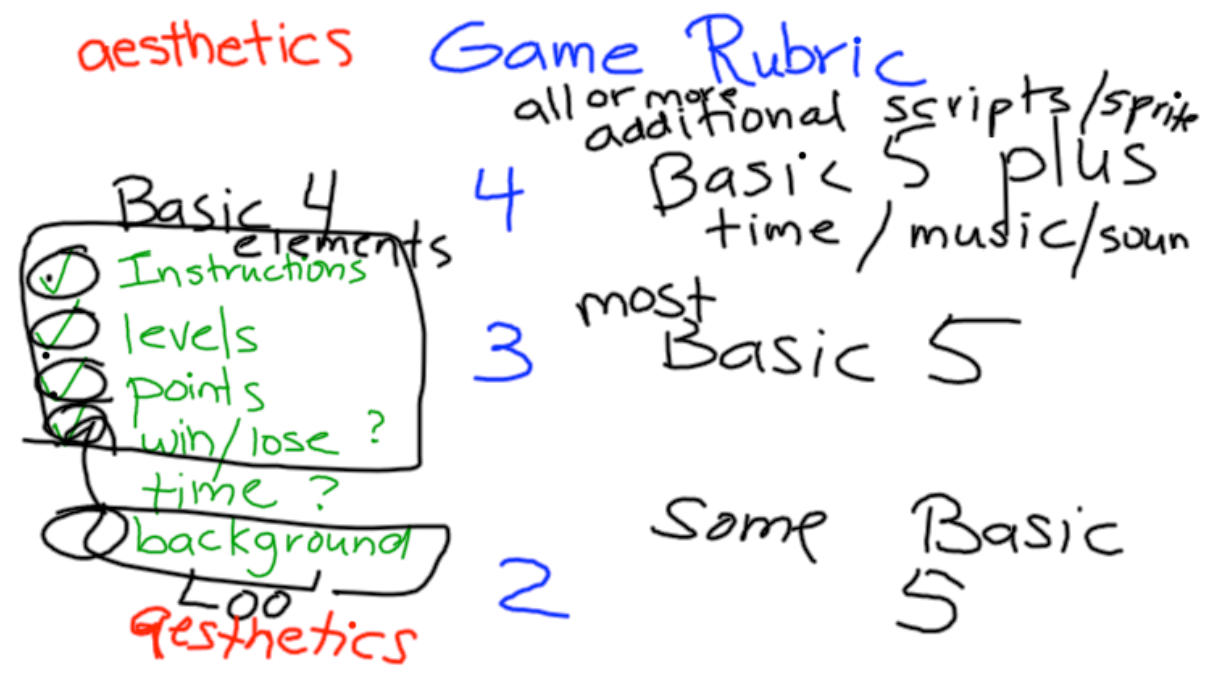

Figure 2B: Sample screen capture of the classroom rubric for scoring games (i.e., the "Basic 5").

Once the list of elements of good game design had been created, students were asked to convert these elements into a scoring rubric for scoring the videogames. Students decided collectively that games would score a "4" on the rubric if they contained all five elements ("the Basic 5") listed in Figure $2 \mathrm{~B}$, plus some additional components. A " 3 " on this rubric would contain 
most of the Basic 5 and a " 2 " would contain some of the Basic 5 elements. Scoring a "1" was not part of the classroom culture and so this was not included in the discussions. One of the elements, "win/lose", lacked complete consensus. This was an interesting point of discussion especially amongst the girls. For several of the girls, the games that they enjoyed playing didn't have a clear winner and loser. In the following excerpt one of the girls speaks up during large group discussion to share her opposing viewpoint:

Teacher: ...Thumbs up if you want your game to have winning or losing in it.

Student: No.

Teacher: $\quad$ No winning or losing? Tell me your reasoning.

Student: Because sometimes me and my friends always don't want winning in some games just because we just want it to be fun.

Teacher: $\quad$...We have to add that, so let's put winning and losing and we'll put a question mark. Winning and losing - win and lose - and we'll put a little question mark here.

This definition of a "game" is at odds with the definition of a game found in the research literature. Professional game designers like Salen (2007) would argue that in order to define something as a game it must have a win and lose condition. However, based on their own perceptions of their playing experiences, several girls in the class argued effectively for applying this criterion flexibly, taking into account other conditions that might make something a good game. This finding is consistent with the literature and points to perhaps why girls are noticeably absent in many after-school programs designed to engage youth in game play or game design (Kafai, 1995; Kafai et al., 2008). More importantly, within this community students were willing to think analytically, connect to past experience, respond to divergent views (even the teacher's), and formulate a counter-argument.

This flexibility in thinking extended to other discussions as well. In one instance, the teacher called upon a shy student to explain why she assigned 3 points to Fish Chomp, a game that lacked most of the five elements from the rubric (a default score of 2, by class standards) (see Figure 3). In doing so, students were asked to evaluate evidence and were thus connecting to another habit of mind central to academic literacy. The student explained, "it didn't have all the basic elements - the basic five - but it was fun to me, so I gave it a three." The class then decided to adjust the rubric to allow 
room for subjectivity, recognizing that sometimes a rubric helps to capture what is going on in the games but that it can also threaten to constrain thinking. This exercise is particularly important for students as they try to better understand how teachers and administrators make qualitative judgments about their work. For game design, it's important to realize that you are designing for a range of users with different interests, likes, and dislikes.

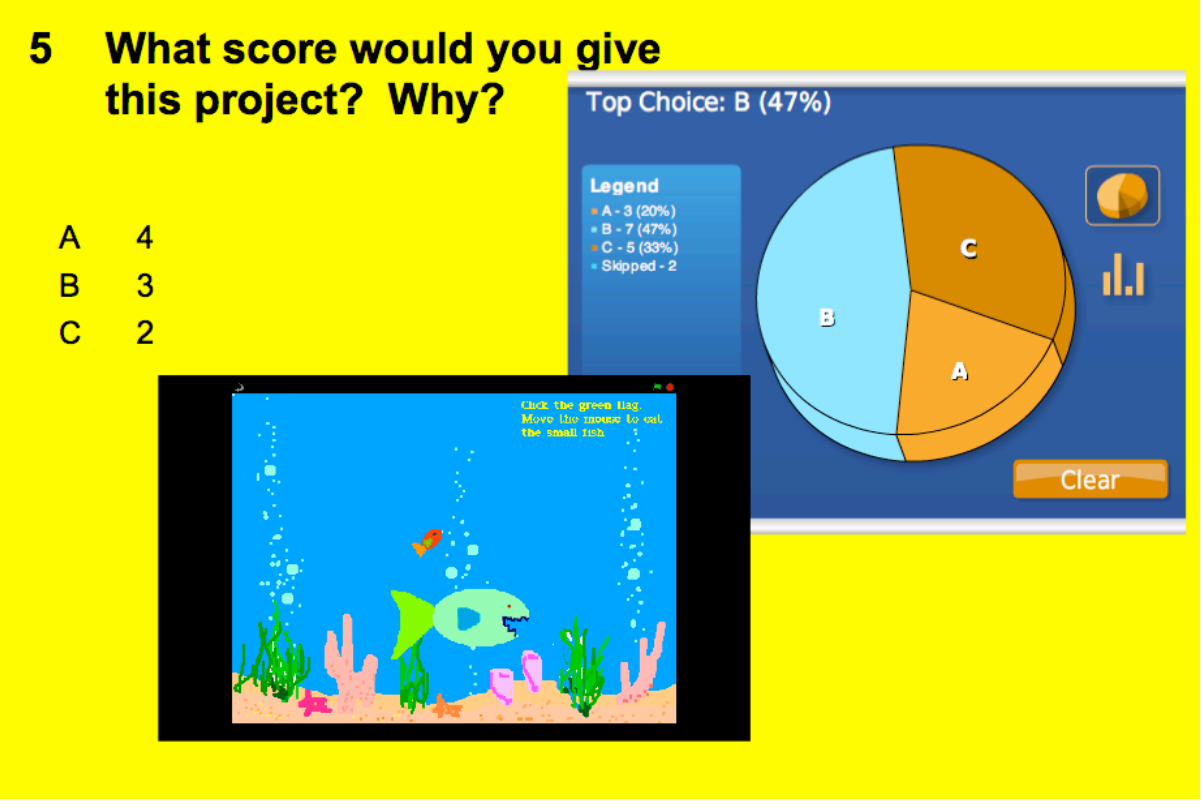

Figure 3: Class B scores for Fish Chomp (47\% of the class gave the game a 3 on a 4 point scale).

In summary, the culture of critique that emerged in the classroom was analytic, mature, and flexible, addressing many of the similar issues and perspectives that might arise among professional game designers. Students demonstrated an ability to seriously evaluate products of a new media genre.

\section{Academic Literacy}

We now turn to our second research question: examining the affordances of game critique for promoting broader goals of academic literacy among youth. We note three findings in this regard. First, the Game Critique unit was a major motivating factor for student writing. The writing output of English Language Learners was substantial and, for those students, sophisticated. The following is a typical writing sample from one of the students that is considered to be at a Level 2 (out of 5) for English 
Language Development (see Figure 4). The writing sample describes his thoughts on the Pinball game:

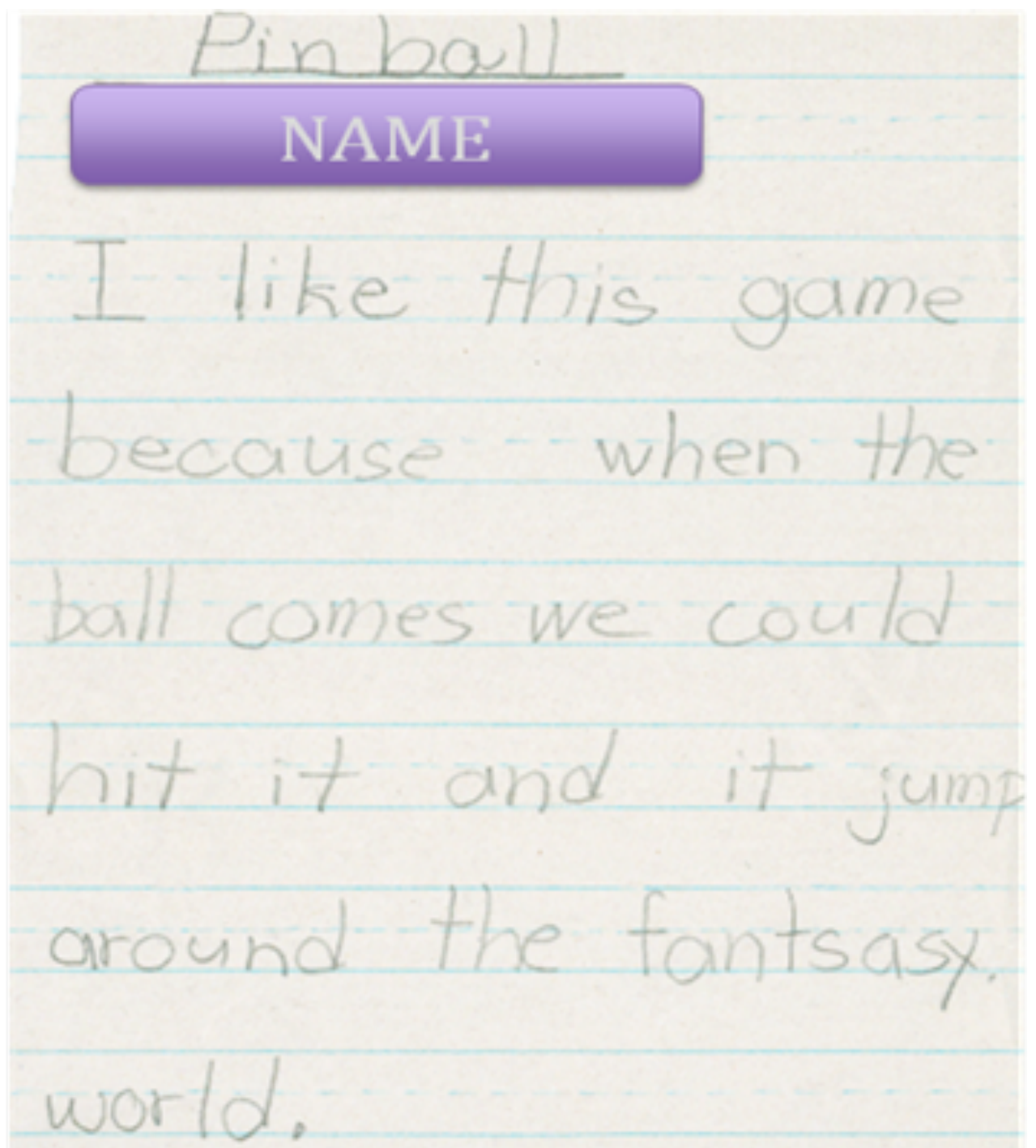

Figure 4: Student writing sample critiquing the game "Pinball".

The student justified his opinion by referring to several aspects of the game, such as user interactivity ("we could hit [the ball]"), genre ("fantasy world"), and game mechanics ("jump around").

Overall, the classroom teacher was particularly struck by the level of engagement in the writing activity. The exercise was only intended to be a 
note-taking activity, not a formal writing exercise, which is why lowquality paper and half-sheets were given to the students. However, as students were writing, they asked for additional sheets of paper, used academic forms of language (e.g., making arguments, presenting thoughts in full sentences), and asked for more time to write down their ideas in full. These types of classroom practices were atypical for the students during their normal class time and were universally taken up by students of all ability levels.

Second, student writing was both reflective and analytical. Students most frequently relied upon value judgments in their written critiques (e.g., liking or disliking aspects of the game), constituting about $55 \%$ of the content of their writings. This was followed by reflection or analysis of the game (e.g., it was hard, easy, fun), which constituted the remainder of the critiques. Students in the study were able to situate their understandings of the game and articulate what they liked and disliked while at the same time reasoning about aspects that were specific to the game and not to their individual preferences. This is a nearly even split between the two types of critiques, both of which seem reasonable given the age group included in the study. The classroom teacher was quick to point out that these types of practices were not typical of their language arts or other subject area participation.

Analysis of the transcripts from the large group discussions yielded similarly well-expressed and thoughtful critiques of aspects of the game. Thus in both their academic discussions and writings students weighed evidence and used the kinds of reflective analyses that are valued in the development of academic literacy (Intersegmental Committee of the Academic Senates, 2002). Interestingly, though the small group conversations acted as brainstorming sessions for the individual writings. each of the student's writings was unique when compared to writings of other students. No two arguments or observations about the games were the same despite the fact that students had initially brainstormed together in small groups prior to writing. This suggested to us that the activity supported articulating ideas, owning ideas, as well as seeking out other viewpoints, all of which are important to academic literacy.

The content of the individual writings covered many aspects of game design important to the professional community, including a great deal of discussion on the merits of individual game components (e.g., sprites/objects, backgrounds, levels, timers and points), game logic and rules (e.g., if you get 500 points, you can go to the next level), the core mechanics of the games (e.g., it's fun to be the "predator" and eat fish), and the aesthetics of the games (e.g., having bright colors, interesting music, or moving seaweed in the background) (see Table 2). At times, students engaged in critique of the narrative or storyline of the games 
despite the lack of narrative or storyline in these sample games. Moreover, the practice of making observations, articulating ideas, and thinking analytically about the various gaming elements all support the development of academic literacy.

Table 2: Elements of Well-Designed Videogames found in the Individual Writings

\begin{tabular}{|l|l|}
\hline $\begin{array}{l}\text { Elements of a Well-Designed } \\
\text { Videogames }\end{array}$ & $\begin{array}{l}\text { Percentage of } \\
\text { Writings } \\
\mathbf{N}=\mathbf{1 0 8})\end{array}$ \\
\hline $\begin{array}{c}\text { Specific Game Components (e.g., } \\
\text { Sprites/Objects, Backgrounds, } \\
\text { Levels, Timers, Points) }\end{array}$ & $85 \%(92)$ \\
\hline Game Logic and Rules & $78 \%(84)$ \\
\hline $\begin{array}{l}\text { Core Mechanics } \\
\text { Interactive Design (Human-Computer } \\
\text { Interaction) }\end{array}$ & $64 \%(69)$ \\
\hline Arts \& Aesthetics & $28 \%(30)$ \\
\hline Story \& Narrative & $11 \%(12)$ \\
\hline NOTE: Writing passages were at times double coded because they contained multiple reasons for why the game
\end{tabular}

NOTE: Writing passages were at times double coded because they contained multiple reasons for why the game was well designed and therefore the percentages do not add to $100 \%$.

Third, we noted that the classroom units explored in this study supported youths' ability to incorporate domain-specific language in their critiques. Part of the difficulty of transitioning from "learning to read" to "reading to learn" for low SES students lies in their lack of knowledge of abstract academic language, as opposed to the more common and concrete vocabulary found in everyday interaction (see discussion in Gee, 2004). Figures $2 \mathrm{~A}$ and $2 \mathrm{~B}$ above show the types of abstract vocabulary that students were exposed to in this lesson, such as "components," "aesthetics", "interactive," "design," "quest," "rubrics," "scripts," and "sprite." To some extent, students began incorporating specialist language in their own conversations and writing. One example is seen above in the English language learner's sample writing (Figure 4); he uses the term "fantasy world," hardly a common everyday expression for a second grader.

\section{Discussion}

This study suggests that game critique can be integrated into school-based curricula to elicit high quality writing and discussion among young children. This also suggests that critique of existing games in a game design curriculum can be used to stimulate discussion. A game curriculum is not only related to a wide array of subject-specific knowledge, but is also built on the students' pre-existing interests in games. The study thus 
suggests that game design and critique can help engage youth in the school curriculum by providing content that resonates with their outside interests.

Additionally, there are more general implications for game and gender studies. Classroom discussions revealed that boys and girls often disagreed about the qualities of good game design. While we have turned to expert game designers and academic researchers to define the field of game studies, we seldom ask young people to make these same judgments. Consequently, youth culture might have very different definitions and ideas of what constitutes a game beyond a win/lose dichotomy. This becomes particularly important as we try to make games for girls and others from disenfranchised communities. Investigating more about the qualities of girl game play can open the possibilities for new educational tools and games for learning.

The activities outlined here also connect in important ways to the development of academic literacy. Students in this study were engaging in the habits of mind that are expected of college-bound youth by responding to divergent views respectfully, by articulating their ideas, by thinking analytically about the work of others, by contributing to academic discussions in both small and large groups, by challenging beliefs (even those held by the teacher), and by evaluating evidence. In addition, students were learning to participate in reading and writing practices that are central to academic literacy in a host of ways, including making an argument, comparing observations or ideas, owning an idea, analyzing texts, reflecting, imagining other possibilities, using past experience, making observations and supporting claims. By tying gaming and academic practices, we also see that classroom activities can support a wide array of learners in core academic literacy practices.

\section{References}

Barton, A. C., \& Rivet, A. (2004). Urban Girls' Science Practices. Teachers College, Columbia University: National Science Foundation.

Barton, D. (1991). The social nature of writing. In D. Barton \& R. Ivancic (Eds.), Writing in the community. Newbury Park, CA: Sage.

Barton, D., \& Hamilton, M. (2000). Literacy Practices. In D. Barton, M. Hamilton \& R. Ivancic (Eds.), Situated Literacies: Reading and Writing in Context (pp. 7-15). London: Routledge.

Bruce, B. C. (2002). Diversity and critical social engagement: How changing social technologies enable new modes of literacy in changing circumstances. In D. E. Alvermann (Ed.), Adolescents and Literacies in a Digital World. New York: Peter Lang Publishing. 
Buckingham, D. (2003). Media Education: Literacy, learning and contemporary culture. Cambridge, UK: Polity Press.

Buckingham, D. and Burn, A. 2007. Game Literacy in Theory and Practice. Journal of Educational Multimedia and Hypermedia, 16 (3). 323--349.

Chall, J. S. (1996). Stages of reading development (2nd Edition). Fortworth: Hartcourt Brace College Publishers.

Chi, M.T.H. (1997). Quantifying qualitative analyses of verbal data: A practical guide. The Journal of the Learning Sciences, 6(3), 271315.

Cummins, J. (2008). Technology, literacy, and young second language learners: Designing educational futures. In L. L. Parker (Ed.), Technology-mediated learning environments for young English learners: Connections in and out of school (pp. 61-98). New York: Lawrence Erlbaum Associates.

Dewey, J. (1980). Art as experience. New York: Penguin Putnam Inc. (Original work published 1934).

Gallas, K. (1994). Languages of Learning: How children talk, write, dance, draw, and sing their understanding of the world. New York: Teachers College Press.

Gee, J. P. (1996). Social Linguistics and Literacies: Ideology in Discourses (2nd Edition ed.). London: Falmer.

Gee, J. P. (2004). Situated language and learning: A critique of traditional schooling. New York: Routledge.

Hagood, M. C., Stevens, L. P., \& Reinking, D. (2002). What do THEY Have to Teach US? Talkin' 'Cross Generations! In D. E. Alvermann (Ed.), Adolescents and Literacies in a Digital World. New York: Peter Lang Publishing.

Hetland, L., Winner, E., Veenema, S. \& Sheridan, K (2007). Studio Thinking: The Real Benefits of Arts Education. New York: Teachers College Press.

Intersegmental Committee of the Academic Senates (2002). Academic Literacy: A Statement of Competencies Expected of Students Entering California's Public Colleges and Universities. Intersegmental Committee of the Academic Senates (ICAS): Sacramento, CA.

Kafai, Y. B. (1995). Minds in play: Computer game design as a context for children's learning. Lawrence Erlbaum Associates: Hillsdale, NJ.

Kafai, Y. B., Heeter, C., Denner, J. \& Sun, J. (2008) (Eds.). Beyond Barbie and Mortal Kombat: New Perspectives on Gender and Gaming. MIT Press: Cambridge, MA.

Kuhn, D. (1991). The skills of argument. Cambridge, UK: Cambridge University Press.

Lave, J., \& Wenger, E. (1991). Situated learning: Legitimate peripheral participation. Cambridge University Press: Cambridge, England. 
Levi, A. W., \& Smith, R. A. (1991). Art education: A critical necessity. University of Illinois Press: Chicago, IL.

Maloney, J., Burd, L., Kafai, Y., Rusk, N., Silverman, B., \& Resnick, M. "Scratch: A Sneak Preview," paper presented at the Second International Conference on Creating, Connecting, and Collaborating through Computing. Kyoto Japan, January 2004.

Marsh, J. (Ed.). (2005). Popular culture, new media and digital literacy in early childhood. New York: Routledge Falmer.

Millard, E. (2003). Towards a literacy of fusion: new times, new teaching and learning? Reading: Literacy and Learning, April, 38.

Moje, E.B. (2000). To be part of the story: The literacy practices of gangsta adolescents. Teachers College Record, 102(3), 651-690.

Morrell, E., and Duncan-Andrade, J. (2004). What they do learn in school: Hip-hop as a bridge to canonical poetry. In J. Mahiri (Ed.) What they don't learn in school: Literacy in the lives of urban youth. New York: Peter Lang, 247-268.

National Research Council (1999). Being Fluent with Information Technology. Washington, DC: National Academy Press.

New London Group. (1996). A pedagogy of multiliteracies: Designing social futures. Harvard Educational Review, 66(1), 60-92.

Osborne, J., Erduren, S., \& Simon, S. (2004). Enhancing the quality of argumentation in school science. Journal of Research in Science Teaching, 41(10), 994-1020.

Peppler, K., \& Kafai, Y. (2007a). From SuperGoo to Scratch: exploring creative digital media production in informal learning. Learning, Media, and Technology, 32(2), 149-166.

Peppler, K. \& Kafai, Y. B. (2007b). What video game making can teach us about learning and literacy: Alternative pathways into participatory culture. In Akira Baba (Ed.), Situated Play: Proceedings of the Third International Conference of the Digital Games Research Association (DiGRA) (pp. 369-376). Tokyo, Japan: The University of Tokyo.

Resnick, M., Kafai, Y., \& Maeda, J. (2003). ITR: A Networked, MediaRich Programming Environment to Enhance Technological Fluency at After-School Centers in Economically Disadvantaged Communities: Proposal submitted to National Science Foundation.

Salen, K. (2007). Gaming Literacies: A Game Design Study in Action. Journal of Educational Multimedia and Hypermedia, 16(3), 301322.

Soep, E. (2005). Critique: Where art meets assessment. Phi Delta Kappan, 87(1), 38-63.

Steinkuehler, C. (2007). Massively multiplayer online gaming as a constellation of literacy practices. eLearning, 4(3) 297-318.

Steinkuehler, C. \& Duncan, S. (in press). Informal scientific reasoning in online virtual worlds. Journal of Science Education \& Technology. 
Street, B. (1993). Cross-cultural Approaches to Literacy. Cambridge: Cambridge University Press.

Squire, K. (2005). Toward a theory of games literacy. Telemedium, 52(12), 9-15.

Warschauer, M., Grant, D., Del Real, G., \& Rousseau, M. (2004). Promoting academic literacy with technology: Successful laptop programs in K-12 schools. System, 32(4), 525-537.

Wohlwend, K. E. (2009). Damsels in discourse: Girls consuming and producing gendered identity texts through Disney Princess Play. Reading Research Quarterly, 44(1), 57-83. 
Table 1: Overview of Selected Games

\begin{tabular}{|c|c|c|}
\hline Game Title & Screenshot & Brief Description \\
\hline $\begin{array}{ll}\text { 1. Fish } \\
\text { Chomp }\end{array}$ & $\begin{array}{r}\because \\
\because \\
\because\end{array}$ & $\begin{array}{l}\text { The object of this game is } \\
\text { to get the big fish to eat } \\
\text { the smaller fish. The } \\
\text { larger fish is controlled by } \\
\text { moving the mouse and } \\
\text { makes a chomping sound } \\
\text { when its mouth touches a } \\
\text { smaller fish. Smaller fish } \\
\text { enter the game at random } \\
\text { intervals, unaffected by } \\
\text { the amount of fish already } \\
\text { consumed (as there are no } \\
\text { points or levels in the } \\
\text { game). The game begins } \\
\text { by pressing the start } \\
\text { button and does not end } \\
\text { until the player presses } \\
\text { the stop button. }\end{array}$ \\
\hline $\begin{array}{l}\text { 2. Treasure } \\
\text { Quest }\end{array}$ & (use < and $\rightarrow$ arrows to move) & $\begin{array}{l}\text { The object of the game is } \\
\text { to catch as many falling } \\
\text { treasure chests as } \\
\text { possible. The player } \\
\text { moves the character side } \\
\text { to side by using the arrow } \\
\text { keys. Treasure chests fall } \\
\text { from the sky at random } \\
\text { locations and at speeds } \\
\text { that gradually increase } \\
\text { depending on the level (1- } \\
\text { 3). Players have } 60 \\
\text { seconds to accumulate the } \\
750 \text { points necessary to } \\
\text { advance to the next level. } \\
\text { A treasure chest icon in } \\
\text { the left corner tallies the } \\
\text { scores during game play } \\
\text { while a bird icon in the } \\
\text { right corner tells the } \\
\text { player how many } \\
\text { additional points are } \\
\text { needed. The character's } \\
\text { animation changes } \\
\text { according to whether or } \\
\text { not a treasure chest is } \\
\text { caught. Each level has its } \\
\text { own background and } \\
\text { music. }\end{array}$ \\
\hline
\end{tabular}




\begin{tabular}{|l|l|}
\hline 3. Pinball & $\begin{array}{l}\text { Similar to traditional } \\
\text { pinball machines, when } \\
\text { the start button is clicked, } \\
\text { a pinball is launched from } \\
\text { the lower right corner of } \\
\text { the screen and bounces } \\
\text { off the objects in the } \\
\text { center of the game. If the } \\
\text { ball touches any of the } \\
\text { objects in the screen, the } \\
\text { objects change shape, } \\
\text { color, and make sounds. } \\
\text { The object of the game is } \\
\text { to keep the pinball from } \\
\text { hitting the bottom of the } \\
\text { screen. The player } \\
\text { controls the red flippers } \\
\text { by using the arrow keys. } \\
\text { To restart the game, the } \\
\text { player must press the } \\
\text { green flag. There are no } \\
\text { points or levels in the } \\
\text { game. }\end{array}$ \\
\hline
\end{tabular}

